\title{
Using Written Tests to assess Holistic Development of Lower Primary School Learners in Kenya
}

Violet R. Otieno

\author{
Masters student, Jaramogi Oginga Odinga University of Science and Technology
}

Dr Benson Charles Odongo

Director, Kosele Learning Centre, Jaramogi Oginga Odinga University of Science and Technology

${ }^{*}$ Dr Peter J.O. Aloka

Department of Psychology, Jaramogi Oginga Odinga University of Science and Technology,

P.O. BOX 210, Bondo, 40601, Kenya

jairopeteraloka@yahoo.com

\section{Doi:10.5901/mjss.2015.v6n3s1p368}

Abstract

The present study investigated the use of written tests to assess holistic development of Lower Primary school Learners in Kenya. The Concurrent Triangulation Design was employed. The sample size comprised 184 respondents who were, 122 lower primary teachers, 47 ECDE teachers and 15 primary school Head teachers.Both Questionnaire and Interviews were used to collect data. The researcher ensured validity of questionnaires through expert judgment that is with the help of lectures from Jaramogi Oginga Odinga University of Science and Technology.Moreover, the items in the questionnaire were made clearer and also arranged from simple to complex. Reliability of the instrument was tested using internal consistency and a reliability coefficient of 0.892 was reported.The quantitative data obtained from questionnaires was analysed by using descriptive statistics with the aid of Statistical Package for Social Sciences (SPSS) version 22. Qualitative data was analysed using the thematic framework. The study finding was that that intellectual development of ECDE learners was effectively assessed by written tests method of assessment. However, on the aspect of emotional development, most participants reported that written tests methods of assessment does not effectively assess emotional development of ECDE learners. Moreover, this study confirms that written tests methods of assessment did not effectively assess the social development of ECDE learners. Finally, most participants disagreed that physical growth andspiritual developments of ECDE learners is assessed well when they are given written tests. The study recommendation is that The Kenya Institute of Curriculum Development should come up with clear policies on assessment of ECDE learners so that holistic development is guaranteed during the assessment process.

Keywords:Written tests, Assessment, Holistic Development, Kenyan, Lower Primary School, Learner

\section{Introduction}

In holistic education, the teacher is not seen as a person of authority who leads and controls but is rather seen as 'a friend, a mentor, a facilitator, or an experienced traveling companion' (Forbes, 2006). Schools should be seen as places where students and adults work towards a mutual goal. Open and honest communication is expected and differences between people are respected and appreciated, co-operation is the norm, rather than competition. Thus, many schools incorporating holistic beliefs do not give grades or rewards. The reward of helping one another and growing together is emphasized rather than being placed above one another. The role of play in supporting children's holistic development, 'meta-cognitive' and self-regulatory abilities is an area of recent research development. Meta-cognitive abilities worry our developing awareness of our own cognitive and emotional processes and expansion of policies to control them (Gronlund, 2006). It is now clearly established that children begin to develop this awareness and control very early in life, important individual differences are quickly established which have long-lasting results for attainment and well-being, that these abilities are learnt, and can be taught, and that the various types of play form a powerful context for their development (Whitebread, 2010).

In United States of America, when assessing Children's Learning and Development, there is specific guidelines that are available regarding children's development. The National Association for the Education of Young Children 
(NAEYC) and the Division for Early Childhood (DEC) advocate the use of authentic assessment practices as the primary approach for assessing young children (DEC, 2007). Early childhood leaders have advocated the use of authentic assessment approaches for accountability purposes, indicating that these methods are more appropriate for young children (Meisels, 2003; Neisworth\&Bagnato, 2004; Grisham-Brown, 2008). Emerging research shows that authentic assessment approaches, used for accountability purposes, can yield technically adequate assessment data thereby not compromising the results of high-stakes assessment.

In Turkey, assessment is done in a structured way, in predetermined times to learn about the development of individual. A number of studies are conducted in Turkey related to assessment and evaluation techniques used by teachers. The result revealed that the teachers face problems in implementing new assessment and evaluation techniques in their classrooms (Gelbal \& Kelecioglu, 2007). These problems might emerge due to teacher's lack of knowledge about implementation of these new constructivist assessment techniques. As a result of their lack of knowledge, they most prefer to use the most familiar assessment techniques for them as exams or face to face interviews. For instance, in the study conducted with elementary school students, researchers investigated assessment strategies used by primary school teachers (Gelbal \&Kelecioglu, 2007). Teachers stated that they mostly prefer to use traditional assessment techniques while assessing their students progress. Teachers find constructivist assessment tools time consuming and leading to extra effort.

In an effort to respond to the need for quality early childhood development and education services the Open Society Initiative for Southern Africa (OSISA; 2009) is focusing increasing attention on providing quality services for young children and their families. The Early Childhood Development and Education Programme is part of the broader OSISA education Programme that seeks to make significant improvements in the early childhood sector in Southern Africa by engaging in multi-leveled interventions in selected countries (Kanje, 2009). The overarching goal of the program, which is being run in collaboration with Open Society Foundation's (OSF) Early Childhood Program, is to promote access to quality early childhood development and education in a manner that places a premium on eliminating inequalities in current access for the most marginalized and vulnerable children.

In the Sessional Paper No. 1 of 2005 on a Policy Framework for Education, Training and Research; the government planned to integrate ECDE into basic education but the policy was not fully implemented, and therefore the ECDE sector is majorly run by private initiatives and partly county government. This has led to the indiscriminate establishment of ECDE institutions with little or no concern for standards in infrastructure, curricula, teaching and assessment methodologies. The task force (2011) appointed by the then minister of education, noted that the current system of education, curriculum and assessment does not include Early Childhood development and education (ECDE). In addition, the quality of education was not clearly spelt out so that the curriculum delivery could focus on development of specific expected competences to be assessed. The task force further noted that the current summative assessment at the end of every cycle does not measure learner's holistic development.

Standardsor quality is currently a challenge to most of the ECDEinstitutions mushrooming all over the urban and rural centres of Kenya; raising eye brows on the capability of the assessment methods used in the country. One great concern is the government's inability to regulate and control the establishment and operations of ECDE in the country whose total effect is the maladjustment on the child not only in terms of cognitive but both psychological and psychomotor wise. Ultimately, the maladjustments have a long term effect on Kenya's development as a whole. In a bid to force formal learning and competition at this early age, most ECDE institutions use a punitive kind of assessment. The children are assessed through exams and assignments and are punished when they fail to meet the threshold (Shitubi and Wanyama, 2012). These punitive methods deny a child the opportunity to develop holistically. The ideal assessment of the children at this early age should be formative and continuous from the experiences planned in a curriculum. This implies documenting the development of the child, by interpreting the day to day experiences of the child with the purpose of recognizing and encouraging strengths and addressing developmental gaps.

It is recommended that teachers use both formal and informal screening and assessment approaches to systematically evaluate children's growth across all domains of development and learning within natural contexts, including the early childhood classroom (Bordignon\& Lam, 2004). In Kisumu central sub-county, ECDE learners especially the ones ready for primary one are strictly assessed formally, leaving one to wonder whether children's growth across all domains of development and learning are really captured. Every society nurtures a set of goals for its children, although the balance among those goals may be contested within societies and may vary across them. People want their children to be safe and healthy, to be happy and well adjusted, to be competent in array of domains and accomplished in one or two of those and to be prepared cognitively and morally to contribute to society. 


\section{Theoretical Framework and Literature Review}

\subsection{Theoretical Framework}

The study was informed by the Humanistic holistic learning theory (Maslow, 1968). The theory is concerned with personal growth and the full development of each human's potential not on just an intellectual level, but also on an emotional psychological, creative, social, physicaland even spiritual level. The goal of education from this point of view is not to simply put a uniform body of knowledge in students 'heads' or to transmit traditional nationalist, instead the goal is to facilitate the development of knowledgeable human beings who know and are able to nature themselves, other humans, and their environment, to instil a joy of learning, to promote the discovery of each student's passion and special talents, and to teach the knowledge and skills necessary for students to be good decision makers (Miller, 1996). The benefit of holistic development among ECDE learners is that the full spectrum of the child or human experience is included in the educational experience. Emotions, relationships creativity, imagination, intuition and real life problems are all part of the human experience. Including them in the educational experience does not take away from learning; rather enhances it. Human educators want to create the conditions where human beings can learn to use their knowledge as well as intellect, emotions and intuition to solve problem, make decisions or come to know the world. They are not trying to produce intellectual automatons, (Gardener, 2000).

Maslow also asserts that schools should produce students who want to learn and know how to learn. Human beings are programmed to want to find out about their world. Learning is a natural process, teachers kill off this natural instinct when they always ask students to learn about things that have no relevance to their lives. When they ask them to learn in ways that are not natural for them. Part of teachers' jobs is to teach students how to learn, that is, how to get the necessary information they need, how to critically analyse and evaluate that information, and how to use and apply it (Miller, 1997). The theory also suggests that students learn best in a non-threatening environment. Threats come not only in the form of physical threats, but also social threats, emotional threats and things that endanger one's self esteem. When schools becomes too much about competition and measuring up, they invariably have a population who experience failure. This population will find something they can be successful in at sooner or later date which may not be very pleasant(Goswami, 1993). Developmentally appropriate practices are a set of standards for providing high quality early care and education experiences to children, birth to 8 , which are based on knowledge about "how children develop and learn".

The theory was relevant since it addresses ways of assessing holistic development. Assessment establishes the child's level of attainment in a learning experience by checking if learning objectives have been achieved and whether progress is being made (Laren, 2008).It enables a teacherto, monitor and promote each child's holistic development plan adequately and understand the learners abilities, evaluate the teaching methods and learning resources in order to adopt relevant teaching and assessing strategies for particular skills, identify children who need remedial assistance to care for individual differences, appraise behavior, skills knowledge, attitudes and achievement of learners and classify learners for further development of skills (Ransuran, 2006).

\subsection{Literature Review}

Numerous studies have investigated assessment of learners in different domains. A study conducted in England by Moss, (2012) on classroom summative assessment involved students between the ages of 4 and 18 years used descriptive survey design to answer the research problem. Data collection instrument was interview guide and the participants of the study were both teachers and students. The findings of the study revealed that when teachers use summative assessments for external purposes like certification for vocational qualifications, selection for employment or further education and or monitoring accountability or gauging the schools performance, students benefit from receiving better description and examples that help them understand the assessment criteria and what is expected of them. The study indicated that only older students respond positively or negatively to written tests and hence their emotions could be assessed. But younger learners take every situation as it comes and therefore their emotions will not be assessed by written test. The study also revealed that when teachers use summative assessment for internal purposes like regular grading, for record keeping, informing decisions about choices within the school and reporting to parents and students, non-judgmental feedback motivates students for further effort. In Pakistan, a study conducted by Hayat (2011) on credibility of written tests or examinations conducted by boards of immediate and secondary education and educational testing and evaluation agency used a sample of 541 students. The study found out that examinations conducted by the educational testing and evaluation agency are more credible than the examinations conducted by the boards, which 
relates to deficiency in administration of the boards. The study also indicated that written test are only credible when assessing intellectual development of learners but cannot in anyway assess the social and moral development of the student.

A study conducted in Uganda by Dozva (2009) on accessibility of early childhood education used 280 parents as the key respondents in the study. Using interview guide as data collection instrument, data was collected from the parents of the sampled area. Survey design was used in the study and descriptive analysis used to analyse the collected data. The study revealed that communities still needed a lot of sensitization regarding ECDE because many still believed that school before primary is a total waste of time. The recommendation of the study was that Early Childhood Education be a pre-requisite to joining primary school. The study also revealed that there was a positive link between early childhood learning and future holistic development of a child which however has been not clearly understood as revealed by Uganda's policy on ECDE. In Kenya, a study conducted by Jagero, (2013) on how performance in Kenya Certificate of Primary (KCPE) can predict their performance in Kenya certificate of secondary education (KCSE ) used expost facto and correlation research design. The major finding was that there was a correlation between performance in KCPE and KCSE and the correlation was significant. The study also indicated that written tests assess the major domains of development in a learner (language, cognitive, social, physical, moral and spiritual development).

From the reviewed literature, some studies were carried out in secondary schools, and they missed information from primary school learners. Therefore the present study was carried out in primary schools but among the ECDE learners, thereby filling gap in literature.Other studies focused on accessibility of early childhood education but not on assessment methods used ECDE's which was the focus of the present study. Other reviewed studies compared two examinations done at the end of eight years in primary and the other done at the end of four years in secondary education but not focusing on lower primary classes. Other studies focused on summative assessment that is done at the end of a course or academic year but not formative, while the present study focused on both the summative and formative assessment thereby filling the gap in literature. Therefore, the present study established the use of written tests to assess holistic development of Lower Primary school Learners in Kenya.

\subsection{Goal of the Study}

The present study investigated the use of written tests to assess holistic development of Lower Primary school Learners in Kenya.

\section{Research Methodology}

\subsection{Research Design}

The study adopted theConvergent Parallel Design. According to Tashakkori and Teddlie (2003), the convergent parallel design (also referred to as the convergent design) occurs when the researcher uses concurrent timing to implement the quantitative and qualitative strands during the same phase of the research process, prioritizes the methods equally, and keeps the strands independent during analysis and then mixes the results during the overall interpretation.For example, an investigator might collect both quantitative correlational data as well as qualitative individual or group interview data and combine the two to best understand participants' experiences. The data analysis consists of merging data and comparing the two sets of data and results (Creswell \& Plano Clark, 2011; Morse \&Niehaus, 2009).

\subsection{Population and Sample}

The target population for the study was 327 respondents. That is, 234 lower primary school teachers, 90 ECDE teachers and 3 DICECE officers in Kisumu Central Sub-county, Kisumu County Kenya. The study used stratified random sampling to select lower primary teachers and ECDE teachers.Stratified random sampling identifies sub-groups in the population and their proportions and select from each sub-group to form a sample (Cooper and Schindler, 2009).Stratified random sampling was found appropriate for this study as it ensures that each sub-group is proportionately represented. Moreover, purposive sampling technique was used to sample the DICECE officers.

\subsection{Research Instruments}

The instruments used in the study were questionnaires to be administered to teachers and interview schedule 
administered to the DICECE officers. The questionnaire were administered to both lower primary and ECDE teachers since they are directly involved in assessment of ECDE learners. Likert's scale was used where the respondents were asked to make a choice based on their opinion whether they Strongly Agree, Agree, Disagree or Strongly Disagree based on the question asked.Interviewing as a research technique involves the researcher asking questions and hopefully receiving answers from the people being interviewed (Kombo and Delno, 2009). The interview schedule was appropriate for the study as it provided in-depth information and a detailed understanding of the issue under research.Validity of questionnaires was ensured through expert judgment that is with the help of lecturers, while reliability was tested using internal consistency and a reliability coefficient of .892 was reported.

\subsection{Data Collection Procedures}

Permission to conduct the study was first sought from Board of post graduate studies of Jaramogi Oginga Odinga University of Science and Technology. After which the researcher obtained research permit from National Council of Science and Technology Innovation (NACOSTI). Then permission from the Kisumu Sub-County Education office was also sought. Thereafter, the researcher obtained permission from Head teachers in schools to be able to conduct study within school. Data collection was through questionnaires which were be administered to lower primary teachers and preschool teachers and interview schedules were administered to the head teachers and DICECE officers. The researcher booked appointments with DICECE officers in advance to facilitate the interview process. Questionnaires were issued to teachers and it took an average of 25 minutes to complete them. Interviews were carried out with the three DICECE officers and the responses were tape recorded.

In order to gain consent of the respondents regarding the study, the researcher showed a written letter of authority and explained the details of the research, its objectives, purpose and procedure before involving in the actual interview or administration of the questionnaires. The privacy of the respondents as well as the confidentiality of their responses was prioritized as well. The researcher also assured the respondents that the data that were collected or gathered was only to be used for the purpose of the study and was to be protected from unauthorized access.

\subsection{Data Analysis}

Data was analysed both quantitatively and qualitatively. Quantitative data was analyzed using descriptive statistics, which quantitatively describes the main features of a collection of information,or the quantitative description itself. The Descriptive statistics aim to summarize a sample, rather than use the data to learn about the population that the sample of data is thought to represent. On the other hand, qualitative data from interviews was analysed using the thematic framework.

\section{Findings and Discussion}

\subsection{Findings}

The study sought to find out teachers' perception on written tests as a method of assessing holistic development of ECDE learners in public primary schools in Kisumu Central Sub-county. An exploration on the ECDE teachers' perception on this was done. The researcher developed a questionnaire designed to evaluate the teachers' views on written test as a method of assessing holistic development of ECDE learners. In exploring teachers' perceptions, items were drawn relating to written tests as a method of assessing holistic development of the learners. They were twelve Likerts'-scaled items type of statements, in which respondents choose from 4-point score; Strongly Agree (SA), Agree(A), Disagree (D) and Strongly Disagree (SD). The respondents were asked to use the scale to respond to the statements in relation to their views on written tests method of assessing ECDE learners. Table 1.

The percentage frequencies of the responses from the ECDE teachers were computed and tabulated as shown in 
Table 1: Percentage frequency response on written tests method of assessment

\begin{tabular}{|c|c|c|c|c|}
\hline ITEM & SA & A & D & SD \\
\hline Written & 0.68 & 42.57 & 29.73 & 27.03 \\
\hline & 0.00 & 33.7 & 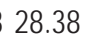 & 7.84 \\
\hline $\begin{array}{l}\text { I development of ECDE learners is effectively assessed by written tests method of } \\
\text { nt. }\end{array}$ & 16.8 & 46. & 10. & 6.35 \\
\hline opment of ECDE learners is effectively assessed by written tests method of asses & 16.89 & 1.35 & & \\
\hline rs. & 16.89 & 0.68 & & .57 \\
\hline Vrittel & 0.00 & 36.49 & & 068 \\
\hline $\begin{array}{l}\text { that physical development of ECDE learners can be well assessed through written tests } \\
\text { essment. }\end{array}$ & 0.00 & 10.1 & 62. & 27. \\
\hline , learners' emotional development is assessed well when teachers give out written tests. & 0.00 & 16. & 56 & 7.03 \\
\hline $\begin{array}{l}\text { Assessment by written tests method is the } \\
\text { development of ECDE learners. }\end{array}$ & 16. & 20. & 20.2 & 42. \\
\hline To as & 16.89 & 25.00 & 40. & 17.5 \\
\hline The most accurate method of assessment when assessing social development of ECDE learners is & 0.00 & 0. & $5608+2)+2>0$ & 43.2 \\
\hline Spiritual development of ECDE learners is assessed well when they are given written & 0.00 & 27.03 & 53.41 & 17.5 \\
\hline
\end{tabular}

From the findings in table 4.1, generally, teachers trust written method of assessment over other methods as they argued that a test should be thought of as an attempt by a student or a learner to demonstrate a mastery of objectives in the specified area of study, hence written work should do this very well. However, the findings of this study showed that a few teachers believed in assessment that is in the form of written work for ECDE learners. About $37 \%$ only of the teacher respondents had a perception that assessment by written tests method is the best when teachers want to assess the intellectual development of ECDE learners, but nearly two thirds (62.84\%) of the ECDE teachers were not keen on using written test for assessing intellectual growth of their learners. The teachers felt that only older students respond positively to written tests assessment of their course work. Nevertheless, about $63 \%$ of those teachers who believed in written form of assessment insisted that intellectual development of ECDE learners is effectively assessed by written tests method of assessment. However, more than a third (34.17\%) of the ECDE teacher still remained firm that written exanimations is not the most appropriate form of assessing an ECDE learners' intellectual development. Qualitative findings also revealed that most of the respondents reiterated the effectiveness of written test method of assessment in assessing the cognitive development of ECDE learners. For example, two respondents reported that,

\begin{abstract}
"Written test method of assessment enhances memory of the child and it also reflects the mental and academic development and reading and writing readiness of the child" (DICECE Officer, A).

"Written test method of assessment helps the teacher to capture all that a child has in mind" (DICECE Officer, B).
\end{abstract}

This means that most respondents agreed that written test method of assessment effectively assess the cognitive development of ECDE learners.

On the aspect of emotional development, those who believed that written tests methods of assessment does not effectively assess emotional development of ECDE learners carried the day at $66.21 \%$, while the ECDE teachers who felt that written test could still be used to assess emotional development lagged behind at $33.78 \%$. In fact, just less than a fifth (18.24\%) of the respondents agreed that emotional development of ECDE learners is effectively assessed by written tests method of assessment, but a whole $81.76 \%$ of the ECDE teachers who participated in this study held a divergent view. Qualitative findings from interviews also revealed that, most of the respondents reported that written test method of assessment cannot assess emotional and spiritual development of ECDE learners. Two respondents reckoned that,

\footnotetext{
"Written test can never show emotional development of the learner" (DICECE officer, C)

"I wonder which method of assessment can effectively assess spiritual development of a child, but I am sure written test method of assessment can never tell how spiritual a child is"'(DICECE officer, A)
}

This means that the respondents believed that the spiritual development and emotional development of a child can never be assessed by written test method of assessment.

In support to other previous findings, this study confirms that written tests methods of assessment does not effectively assess the social development of ECDE learners, as was observed by more than four fifth (81.72\%) of the 
respondents. In fact, nearly all (99.32\%) of the ECDE teachers from Kisumu Central sub-county, who took part in this study, refuted the claim that the most accurate method of assessment when assessing social development of ECDE learners is written test method.On spiritual development as an important aspect of holistic growth, $72.98 \%$ (disagree: $55.41 \%$; strongly disagreed: $17.57 \%$ ) generally disagreed that spiritual development of ECDE learners is assessed well when they are given written tests and only $27.03 \%$ of the respondents were in support of the opinion. On whether written test method was effective or not, only $36.49 \%$ of the respondents agreed that written tests methods of assessment effectively assess the spiritual development of ECDE learners and $50.68 \%$ of them strongly disagreeing another $12.84 \%$ just disagreeing that that written test are suitable for assessing ECDE learners spiritual development.

The physical growth and development which is essential aspect of holistic development of ECDE learners, does not require written tests to be gauged. This was the point of view of the majority (89.76\%) of the respondents, they negated the claim that that physical development of ECDE learners can be well assessed through written tests method of assessment; only $10.14 \%$ of the ECDE teachers agreed written tests could still be used to assess physical growth of the ECDE learner. Whereas only $42.57 \%$ of the ECDE who said written test could be used to measure physical development agreed that it is effective method, $56.76 \%$ of them said that even if written tests method is used it was not effective method to assess physical development of ECDE learners.Qualitative findings from interviews revealed that some respondents reported that written tests method of assessment was very effective in assessing the physical development of ECDE learners. For example two respondents reported that,

"Written test method of assessment enables learners to develop their small locomotion muscles" (DICECE Officer, A). "Written test method of assessment helps learners develop their finger muscles and also develop eye finger coordination" (DICECE Officer, B)

This means that the respondents felt that physical development of ECDE learners can effectively be assessed be assessed by written tests method of assessment.

Lastly, another component of education that forms integral part of holistic growth and development of the learner is the moral aspect. Here again, majority (68.11\%; disagree:40.54\%, strongly disagree:17.57\%) of the respondents held the view that written tests method of assessment is not very effective for assessing the level of moral development, only $16.89 \%$ of the teachers who participated in this study agreed that assessment moral development of ECDE learners can be done through written tests.

\section{Discussion}

The findings were that most teachers who believed in written form of assessment insisted that intellectual development of ECDE learners is effectively assessed by written tests method of assessment. This was affirmed by qualitative findings where most of the respondents reiterated the effectiveness of written test method of assessment in assessing the cognitive development of ECDE learners. However, more than a third of the ECDE teacher still remained firm that written exanimations is not the most appropriate form of assessing an ECDE learners' intellectual development. This is contrary to Wangechi (2014) in Kenya whose study revealed that written tests put more emphasis on intellectual development and academic preparation for later schooling and domains such as spiritual and emotional domains have been ignored by written tests. The implication of this finding is that teachers and parents should be sensitized not to insist on written test method of assessment, they should be aware of the fact that they are only assessing one domain of development, the cognitive domain. This is contrary to philosophy of ECDE which embraces more of nurturing than of direct instruction.

The findings were that, those who believed that written tests methods of assessment does not effectively assess emotional development of ECDE learners were at three quarters of teachers. The Qualitative findings from interviews also revealed that, most of the respondents reported that written test method of assessment cannot assess emotional and spiritual development of ECDE learners. This finding is supported by Moss (2012) in England whose study indicated that only older students respond positively or negatively to written tests and hence their emotions could be assessed. But younger learners take every situation as it comes and therefore their emotions will not be assessed by written test. This study confirms that written tests methods of assessment does not effectively assess the social development of ECDE learners, as was observed by more than four fifth of the respondents. This finding is in agreement with Hayat (2011) in Pakistan whose study indicated that written test are only credible when assessing intellectual development of learners but cannot in anyway assess the social and moral development of the student. Most participants also reported that spiritual development is not well assessed by given written tests.

This was the point of view of the majority of the respondents, they negated the claim that that physical 
development of ECDE learners can be well assessed through written tests method of assessment. This means that the respondents felt that physical development of ECDE learners can effectively be assessed be assessed by written tests method of assessment.This is contrary to Jagero (2013) in Kenya whose study indicated that written tests assess the major domains of development in a learner (language cognitive social physical moral and spiritual development).

Finally, majority of the respondents held the view that written tests method of assessment is not very effective for assessing the level of moral development. This finding is in agreement with Hayat (2011) in Pakistan whose study indicated that written test are only credible when assessing intellectual development of learners but cannot in anyway assess the social and moral development of the student.However, Dozva (2009) study reiterates that there is a positive link between early childhood learning and future holistic development of a child which however has been not clearly understood.

\section{Concluding Remarks}

The study investigated the use of written tests to assess holistic development of Lower Primary school Learners in Kenya.Most of the respondents reiterated the effectiveness of written test method of assessment in assessing the cognitive development of ECDE learners. However, more than a third of the ECDE teacher still remained firm that written exanimations is not the most appropriate form of assessing an ECDE learners' intellectual development.Those who believed that written tests methods of assessment does not effectively assess emotional, social, moral and physical development of ECDE learners were at three quarters of teachers.

From the findings of the study, the study recommends that the Kenya Institute of Curriculum Development should come up with clear policies on assessment of ECDE learners so that holistic development is guaranteed during the assessment process. Moreover, the Kenyan Ministry of Education should come up with specific methods of assessment that are appropriate for holistic development of ECDE learners and hence review the curriculum on the same.

\section{References}

Creswell, J. W., \& Plano Clark, V. L. (2011). Designing and conducting mixed methods research. (2nd ed.). Thousand Oaks, CA: Sage.

Dozva, M. (2009). Strategies used by Chitungwiza day care centre caregivers to deal with separation anxiety in preschool, Zimbabwe. Journal of Educational Research.(3), 358-374

Gardener, H. (1993) Multiple Intelligence. The theory in practice. New York: Basic Books

Goswami, A, Reed, R. \&Goswami, M. (1993). The self-aware universe: How consciousness creates the material world. New York, Putnam Books.

Grisham-Brown, J. (2008). Best practices in implementing standards in early childhood education. In A. Thomas \& J. Grimes (Eds.), Best practices in school psychology V (pp. 1025- 1042). Washington, D.C.: National Association of School Psychologists. Texas: Psychological.

Gronlund, G., (2006). Make early learning standards come alive: Connecting your practice and curriculum to state guidelines. St. Paul, MN: Redleaf Press.

Kanjee, A. (2009). Enhancing teacher assessment practices in South African schools: Evaluation of the assessment resource banks. Education and Change, (1) pp $67-83$.

Kombo, D K \&Delno, L. A. T (2009).Proposal and Thesis Writing: An Introduction.Nairobi; Pauline's publication Africa.

Maslow, A. (1968). Towards a psychology of being. (3th ed). New York.

Meisels, S. J., Atkins-Burnett, S., Xue, Y., Bickel, D. D., \& Son, S. (2003). Creating a system of accountability: The impact of instructional assessment on elementary children's achievement test scores.. Education Policy Analysis Archives, (9), 1-18.

Miller, J. (1996). The holistic curriculum. Toronto. OISE Press.

Miller, R. (1997). What are schools for?Holistic Education in American culture (3 ${ }^{\text {rd }}$ edition). Brandon, VT. Holistic Education Press.

Morse, J., \&Niehaus, L. (2009). Mixed method design: Principles and procedures. Walnut Creek, CA: Left Coast Press.

Neisworth, J., \&Bagnato, S. J., (2004).The mismeasure of young children: The authentic assessment alternative. Infants and Young Children, (17), 198-212.

Ransuran, A. (2006). 'How are teachers' understandings and practices positioned in discourses of assessment?' paper presented at the $4^{\text {th }}$ Sub-regional conference on Assessment in Education. Johannesburg, South Africa, 26 thto 30th June 2006.

Tashakkori, A. \&Teddlie, C. (2003). Handbook of mixed methods in the social and behavioral research. Thousand Oaks, CA: Sage.

Whitebread, D. (2010). Play, metacognition and self-regulation.In P. Broadhead, J. Howard and E. Wood (Eds.). Play and learning in the early years. London: Sage. 